\title{
Recursos didáticos como estratégia de geoeducação: um meio para fomentar o geoturismo no projeto Geoparque Caminhos dos Cânions do Sul
}

\author{
Sinval Pereira Júniora; Patrícia Fagundes Gomesb; \\ Janete Rodrigues Bondanc; Leila Maria Vasquez Beltrãod
}

\section{RESUMO}

O presente estudo aborda os recursos didáticos desenvolvidos para os alunos do $6^{\circ}$ ano da Rede Municipal de Educação Básica de Jacinto Machado/SC, com vistas a contribuir para a geoeducação. De forma lúdica e interativa, os recursos visam ilustrar a origem, os processos e a definição de parte do patrimônio geológico inventariado no território do Projeto Geoparque Caminhos dos Cânions do Sul (GCCS). A iniciativa tem como pressuposto o entendimento de que as ações de geoturismo e de geoconservação devem estar associadas com as da geoeducação, para que possam envolver todas as instâncias da comunidade e consolidarem-se como alternativas concretas para o desenvolvimento social, econômico e cultural. Utilizando-se da pesquisa-ação como definição metodológica, o estudo desenvolveu quatro recursos didáticos que serão aplicados na Rede Municipal de Ensino de Jacinto Machado/SC e que poderão ser replicados a todos os sete municípios incluídos no Projeto GCCS.

\section{Palavras-chave}

Geoturismo

Geoeducação

Recursos Didáticos

Projeto Geoparque Caminhos dos Cânions do Sul 


\section{INTRODUÇÃO}

Sete municípios, entre os Campos de Cima da Serra e do litoral norte do Rio Grande do Sul, bem como do Extremo Sul de Santa Catarina, compõem o perímetro do Projeto Geoparque "Caminhos dos Cânions do Sul" (GCCS). Os municípios de Morro Grande, Timbé do Sul, Jacinto Machado e Praia Grande, em Santa Catarina e Torres, Mampituba e Cambará do Sul, Rio Grande do Sul estão concentrados em ações que visam submeter a candidatura à UNESCO, entidade que em conjunto com a GGN (Global Geoparks Network), concede o selo de Geoparque.

Figura 01 - Localização do território do Projeto GCCS

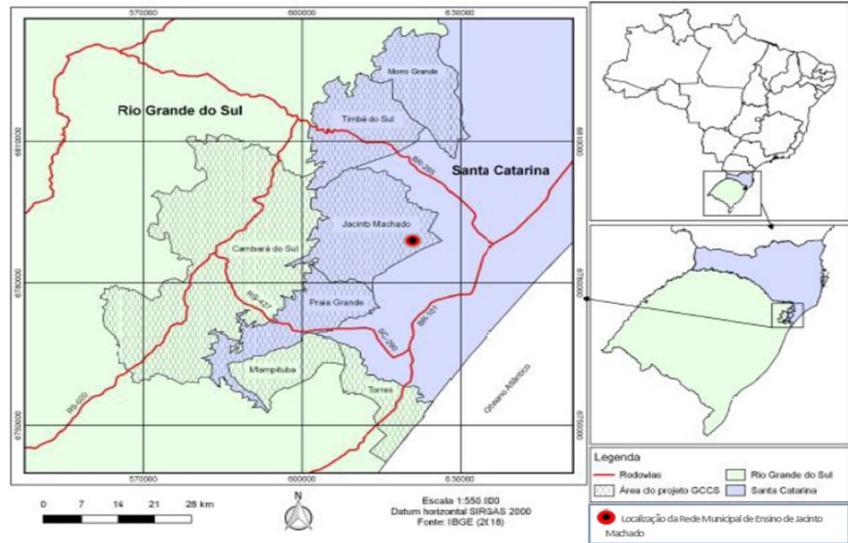

Fonte: adaptado de Geodiversidade (2018).

A UNESCO/GGN concede o selo aos territórios que apresentem uma estratégia de desenvolvimento socioeconômico, baseada no turismo com ênfase no patrimônio natural (geodiversidade e biodiversidade) e nos patrimônios histórico, arqueológico e cultural (gastronomia, artesanato e tradições) da região (UNESCO, 2014).

É indispensável que haja participação e engajamento da sociedade civil e dos órgãos governamentais na gestão do território. Trata-se, portanto, de abraçar todas as instâncias da comunidade e propor uma forma de crescimento que incorpore o geoturismo e a geoconservação do patrimônio natural como alternativas concretas para o desenvolvimento social, econômico e cultural.

A proposta da UNESCO/GGN baseia-se em dimensões-chave para a gestão do território dos Geoparques, organizados em um tripé: o geoturismo, a geoconservação e a geoeducação. No geoturismo, entendido como a atividade turística com conotação geocientífica, propõe-se a visita organizada e orientada a locais que testemunham uma fase do passado ou da história de origem e evolução do planeta, que se notabilizam como uma herança coletiva que deve ser preservada para as gerações futuras (Moura-Fé, Nascimento \& Soares, 2017).

Logo, os acessos aos sítios geológicos e às belezas paisagísticas, os serviços de sinalização, a hospedagem e informação turística, a organização das atividades culturais são alguns dos aspectos que devem ser propiciados pelo geoturismo. Contudo, tal segmento deve ter como premissa a adoção de um modelo de exploração que esteja focado na sustentabilidade da atividade e do recurso (Lin, Beltrão \& Melo, 2016). Assim, fomentar e ampliar os diversos serviços turísticos (meios de hospedagem, alimentação, transportes, agenciamento, etc.) e a infraestrutura turística são ações necessárias, desde que não promovam a degradação.

Em tal perspectiva, Moreira (2014) destaca a importância de planejar este segmento do turismo, minimizando o quadro de impactos negativos no destino. Para executar as ações de planejamento, a autora propõe as seguintes etapas:

a) Inventário dos pontos de interesse

b) Definição de objetivos e metas

c) Desenvolvimento de ações

d) Gerenciamento, avaliação e monitoramento

Tais medidas terão força para desenvolver o turismo local de modo sustentável, utilizando a paisagem para o fazer turístico, sem causar danos ao patrimônio natural e geológico.

Assim, promover o geoturismo, pressupõe uma atenção especial para as ações de geoconservação. A geoconservação é um campo ainda novo, contudo vem crescendo rapidamente e cujo objetivo, em sentido amplo, é "a utilização e a gestão sustentável de toda a geodiversidade, englobando todos tipos de recursos geológicos" (Brilha, 2005, p. 51).

Para tal o autor reconhece pontos de destaque do patrimônio geológico, inventariados e bem delimitados geograficamente, onde ocorrem um ou mais elementos da geodiversidade com singular valor científico, pedagógico, cultural e turístico: são os geossítios (idem).

Contudo a geoconservação nunca será totalmente eficiente enquanto estiver restrita às ações do poder público e dos profissionais e empreendedores envolvidos com o geoturismo. Ela deve ser uma prática internalizada por toda a comunidade que entende o valor de seu patrimônio natural, o respeita e está efetivamente envolvida com a sua conservação. Logo, 
não é possível pensar em geoconservação e geoturismo sem refletir sobre geoeducação, o terceiro item do tripé proposto pela UNESCO/GGN.

A geoeducação é pensada, no presente, como um ramo específico da educação ambiental a ser aplicado na geoconservação, compreendendo ações que podem ser desenvolvidas em âmbitos formais e/ ou não formais do ensino (Moura-Fé, Nascimento \& Soares, 2017).

As atividades geoeducativas fazem parte do planejamento do geoturismo, pois Moreira (2014) afirma que na terceira etapa de planejamento "desenvolvimento de ações" - é importante levar em consideração a inserção de temas voltados ao patrimônio geológico regional no âmbito educativo, abordando tais conteúdos em escolas e universidades locais. Newsome \& Dowling (2006) destacam ainda que a prática educativa é um fator chave para fomentar um destino geoturístico.

No âmbito do Projeto GCCS, essa dimensão-chave é um desafio amplo. Ações já foram e continuam sendo realizadas, através do Comitê Gestor, do Comitê Educativo Científico da candidatura e dos diversos parceiros institucionais. No entanto, há uma solicitação frequente dos professores de escolas da região no sentido de desenvolver recursos didáticos para o ensino das Geociências voltadas à geoeducação local, de forma adequada ao público escolar da Educação Básica.

Assim, visando articular novos vetores de ação e suprir a demanda apresentada, destaca-se a necessidade de desenvolver recursos didáticos para ressignificar a geoeducação na Educação Básica.

É importante destacar que os temas relacionados à dinâmica da Terra, apesar de inseridos nos Parâmetros Curriculares Nacionais - PCNs (Brasil, 1998a; Brasil, 1998b) e na Base Nacional Comum Curricular - BNCC (Brasil, 2016a), nas disciplinas de Geografia e Ciências, permanecem sendo tratados de forma superficial e desconectados da realidade do educando, pois estão comumente dissociados de sua manifestação local, tornando-se um conteúdo pouco explorado e de difícil assimilação (Alencar, 2013).

Neste sentido, o presente trabalho teve como foco contribuir para mudança do referido quadro, desenvolvendo recursos pedagógicos de geociências para os docentes de Educação Básica da Rede Municipal de Ensino - RME de Jacinto Machado/SC, em especial para a disciplina de Geografia do $6^{\circ}$ ano do Ensino Fundamental.
Tais materiais, de baixo custo, visam integrar a geodiversidade do Projeto GCCS com os temas de geociências trabalhados nas escolas, disseminando de forma lúdica e interativa, conhecimentos que possam levar à compreensão sobre a origem, os processos e a definição do patrimônio geológico regional, contribuindo para a Geoeducação e Geoturismo no âmbito do território do Projeto GCCS.

O presente estudo de abordagem qualitativa, enquadra-se como pesquisa-ação, já que irá gerar um resultado prático (Gil, 2010). Para tal, fez-se o uso da pesquisa bibliográfica, objetivando encontrar modelos de recursos didáticos já aplicados em outras localidades de importância geológica e adaptá-los à realidade do Projeto GCCS.

\section{MetOdologia}

Assim, o presente estudo exploratório (Triviños, 2011) desenvolveu-se em quatro etapas:

a. pesquisa em material bibliográfico sobre os conteúdos de geociências trabalhados no Ensino Fundamental

b. pesquisa bibliográfica acerca de recursos didáticos ligados à geoeducação que podem ser adaptados à realidade a ser trabalhada

c. adaptação do material pesquisado às características e especificidades do território do Projeto GCCS e à rede de ensino a ser aplicada

d. construção dos recursos didáticos desenvolvidos e adaptados.

Paralelamente, realizou-se um diálogo com os professores de Geografia das três escolas que compõem a Rede Municipal de Educação Básica de Jacinto Machado/SC, acerca das dificuldades e expectativas para o aperfeiçoamento do processo educativo em geociências no $6^{\circ}$ do Ensino Fundamental, especialmente no que tange a integração desses conhecimentos com a realidade local.

\section{Resultados}

A partir de um estudo preliminar desenvolvido por Beltrão et al (2018) obteve-se um comparativo entre os PCNs, exemplares de livros didáticos do Ensino Fundamental - EF disponíveis no mercado e os Planos de Curso - PCs em execução na RME de Jacinto Machado/SC. Tal estudo apontou, com base 
nos PCNs, quais temas de geociências devem ser trabalhados no EF, por quais disciplinas e em qual ano encontram-se concentrados. Tais informações foram comparadas com os PCs da RME de Jacinto Machado, verificando-se a concentração das temáticas de geociências no $6^{\circ}$ ano do $E F$, na disciplina de Geografia.

Com base no referido estudo, selecionou-se parte dos conteúdos para elaboração dos materiais didáticos, analisando-se as necessidades relatadas pelos docentes, o levantamento bibliográfico sobre recursos pedagógicos utilizados ao ensino de geociências para - EF e a geodiversidade presente no território do Projeto GCCS. Tal procedimento permitiu definir quais os materiais deveriam ser desenvolvidos, chegando-se às correlações especificadas na figura 02.

Figura 02 - Conteúdos de geociências selecionados para elaboração do material didático

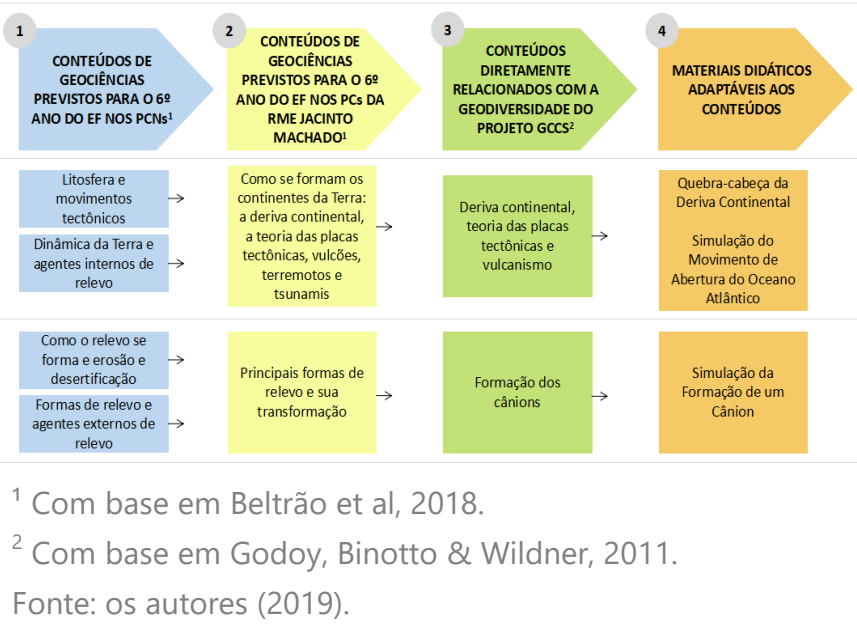

Após realizar pesquisas em material bibliográfico, iniciou-se o processo de adaptação e criação dos recursos didáticos, buscando adequá-los aos conteúdos trabalhados no $6^{\circ}$ ano do Ensino Fundamental. Cada material é apresentado a seguir.

\section{Quebra-cabeça da Deriva Continental}

Partindo do modelo em MDF disponibilizado por Sung Chen Lin e elaborado com base em Godoy, Binotto \& Wildner (2011), o recurso pedagógico foi construído com placas de EVA (espuma vinílica acetinada) de 0,7 $\mathrm{cm}$ de espessura. Buscou-se a utilização de cores contrastantes e de espessura que fornecesse flexibilidade e resistência ao material. Selecionou-se ainda um material de baixo custo e que pôde ser manipulado, de forma artesanal, pelos autores.

O material pedagógico é composto de um conjunto de cinco quebra-cabeças, cada um referente a posição dos continentes em relação ao tempo geológico. Para contribuir no trabalho do professor, desenvolveu-se um Manual de Instruções que descreve, de forma minuciosa, os processos geológicos envolvidos em cada um dos momentos retratados nos quebracabeças, sua manifestação concreta no território do Projeto GCCS, através da exposição dos geossítios representativos de cada fase, bem como sugestão de metodologias para o uso do material pelo professor, buscando integrar o conhecimento teórico ao prático. Tal conteúdo é sintetizado a seguir (figura 3).

Figura 3 - Quebra-cabeça nº 01

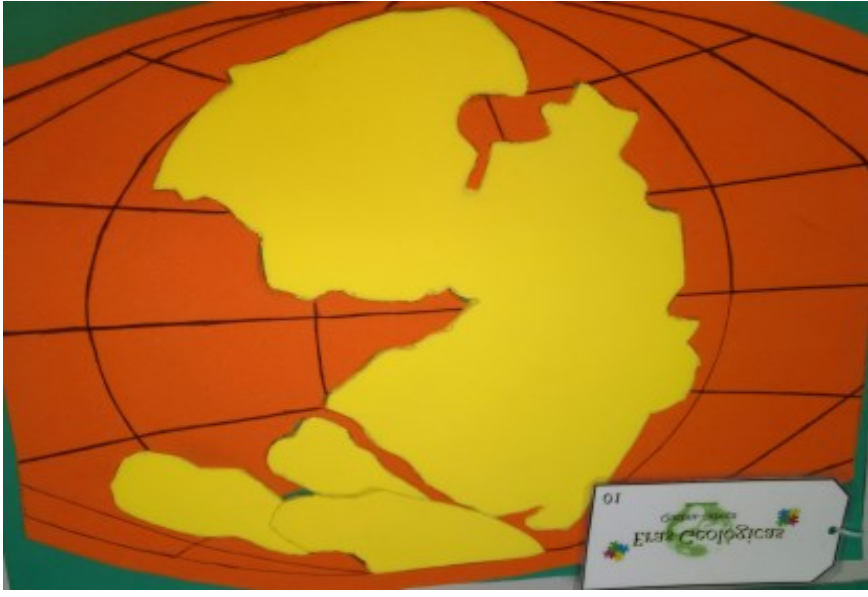

Fonte: autores (2019).

\section{Síntese de informações do Quebra-cabeças nº 01}

\section{DESCRIÇÃO DOS PROCESSOS GEOLÓGICOS-} GEOMORFOLÓGICOS: Refere-se à era geológica Paleozóica, período Permiano, a cerca de 255 milhões de anos atrás (Brasil, 2016b). Existência de um único supercontinente (Pangeia), cercado por um oceano interno conhecido como Mar de Tethys.O período foi marcado pelo predomínio do clima seco e um mar intracontinental entre o sul da América do Sul e a África. Tal depressão evoluiu para uma enorme bacia sedimentar cujos ambientes deposicionais variaram do marinho raso até e lacustre e flúvio-deltaico, o que no sul do Brasil originou a Formação Rio do Rastro (Warren, 2008).

GEOSSÍTIOS DO PROJETO GCCS - Há três geossítios da Formação Rio do Rastro (Geodiversidade, 2018). Neles é possível encontrar depósitos sedimentares intercalados com a presença de arenitos finos, argilitos avermelhados e siltitos (Godoy, Binotto \& Wildner, 2011; Geodiversidade, 2018). Os geossítios representativos do período são: Mineração Angelgrés e Cachoeira do Tatu em Morro Grande (SC) e Cachoeira Rio do Salto em Timbé do Sul (SC).

METODOLOGIAS ADICIONAIS SUGERIDAS - Sugere-se atividade de campo com os alunos, onde poder-se-á 
observar a coloração, espessura, deposição e textura dos materiais depositados, provavelmente, em forma de lamas, ao longo de áreas de planície de inundação, no delta de rios existentes à época (Warren, 2008).

\section{Síntese de informações do Quebra-cabeças n 02}

\section{DESCRIÇÃO DOS PROCESSOS GEOLÓGICOS-} GEOMORFOLÓGICOS - Retrata a era Mesozóica, no período Triássico Superior, há cerca de 200 milhões de anos (Brasil, 2016 b), quando Pangeia sofreu a ruptura que originou os continentes da Laurásia e de Gondwana (Winge et al, 2001).

Figura 4 - Quebra-cabeças nº 02 - Laurásia e Gondwana

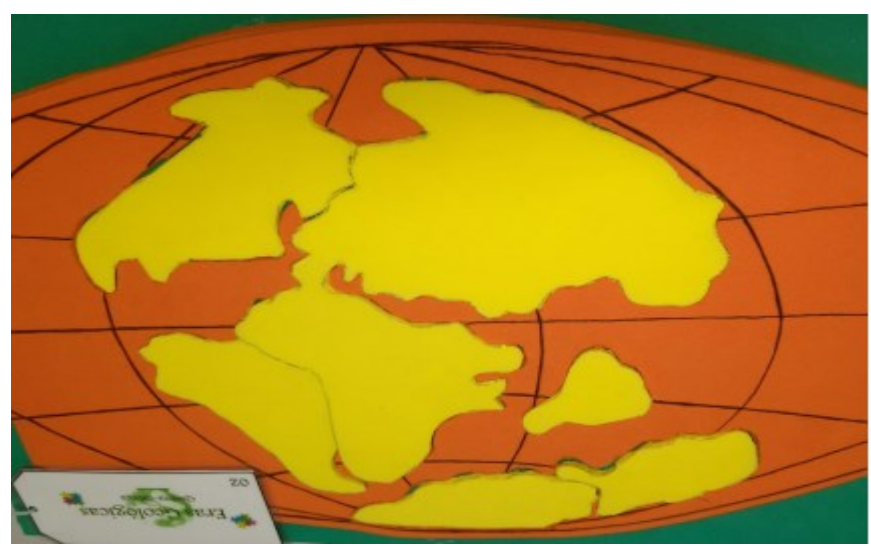

Fonte: autores (2019).

No sul de Gondwana o clima árido gerou o preenchimento de uma gigantesca bacia com sedimentos arenosos. As condições de aridez estendiam-se por partes dos atuais continentes sul americano, africano e antártico (Godoy, Binotto \& Wildner, 2011). Na América do Sul o processo deu origem à Bacia do Paraná, a partir do Jurássico, onde as areias depositadas transformaram-se em arenitos da Formação Botucatu (Sgardi e Dadenne, 1996).

GEOSSÍTIOS DO PROJETO GCCS - Há dez geossítios inventariados (Godoy, Binotto \& Wildner, 2011; Geodiversidade, 2018) que representam testemunhos desse período evolutivo. Eles podem ser agrupados em três tipologias: as paleotocas, os relevos residuais e as áreas de contato com a Formação Serra Geral.

As paleotocas, destacam-se por sua importância paleontológica, pois foram esculpidas por animais da megafauna sul americana como os tatus e as preguiças gigantes (Buchmann, 2017) em arenitos eólicos pouco cimentados do deserto de Botucatu. No perímetro do Projeto GCCS as paleotocas já inventariadas localizamse nos municípios de Timbé do Sul, Morro Grande e Jacinto Machado existindo, contudo, inúmeras cavernas de mesma origem, ainda não estudadas.
Os geossítios de relevos residuais são produto da erosão regressiva da escarpa da Serra Geral, ao longo do Cenozóico (Godoy, Binotto \& Wildner, 2011), que formam extensos alinhamentos serranos, espigões ou morros testemunhos (como o Morro Itaimbé, em Jacinto Machado-SC), a ação da água sobre fraturas (Fenda da Raia, Timbé do Sul-SC) ou erosão diferencial em camadas horizontais como a base do Paredão da Areia Branca, Timbé do Sul-SC (Geodiversidade, 2018). Já os geossítios Cascata do Padre (Geodiversidade, 2018), Morro da Moça, Parque da Guarita e Morro Carasal (Godoy, Binotto \& Wildner, 2011) representam zonas de contato entre a Formação Botucatu e a sua sucessora, a Formação Serra Geral, cuja origem está relacionada ao quebra-cabeça número 03.

METODOLOGIAS ADICIONAIS SUGERIDAS - Sugere-se a exploração dos processos de formação do arenito (cimentação da areia), seus usos econômicos, bem como a abordagem sobre a fauna das eras pretéritas. Caso haja a possibilidade de saídas de campo, as paleotocas são muito educativas pois permitem diversos tipos de interação entre a geologia, a paleontologia, a história (povos pré-colombianos) e a cultura (lendas e causos).

\section{Síntese de informações do Quebra-cabeças n03}

\section{DESCRIÇÃO DOS PROCESSOS GEOLÓGICOS-} GEOMORFOLÓGICOS - Refere-se à posição dos continentes na era Mesozóica, período Jurássico Superior, há cerca de 135 milhões de anos atrás. Ilustra o processo de ruptura de Gondwana, que separou a América do Sul da África, originando o Oceano Atlântico. No processo abriram-se fraturas diagonais e paralelas por onde teve início um vulcanismo fissural (Leinz \& Amaral, 1989). A extensão desses derramamentos chegou a 1,2 milhão de Km2 na Bacia

Figura 05 - Quebra-cabeças nº 03 (Início da ruptura entre América do Sul e África)

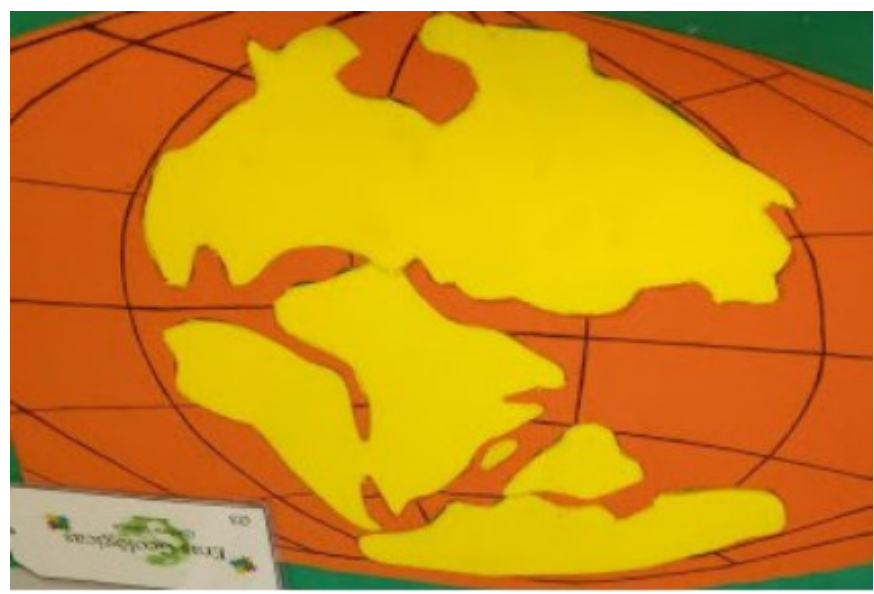

Fonte: autores (2019). 
do Paraná e 78 mil km2 na Bacia de Etendeka (Namíbia/África).

Segundo Godoy, Binotto \& Wildner (2011), os magmas lançados durante o movimento tectônico divergente, ascenderam na crosta através de pontos quentes (hot spots) responsáveis pela movimentação divergente das placas tectônicas. Os derrames magmáticos deram origem, na América do Sul, à Formação Serra Geral, com a presença de derrames básicos (basaltos) e ácidos (riolitos e riodacitos). A Serra Geral é dotada de uma escarpa íngreme (onde há o processo de formação dos cânions) que resultou do soerguimento ocorrido entre o final do Cretáceo (Mesozóico) e ao longo de todo o Terciário- Cenozóico (Godoy, Binotto \& Wildner, 2011).

GEOSSÍTIOS DO PROJETO GCCS - Não há geossítios específicos desse momento no território do Projeto GCCS. Contudo avaliou-se ser importante sua inclusão no kit, pois os processos ilustrados são fundamentais para a compreensão dos períodos posteriores.

METODOLOGIAS ADICIONAIS SUGERIDAS - Para ilustrar a ruptura de Gondwana, desenvolveu-se o modelo de Simulação do Movimento de Abertura do Oceano Atlântico (material didático descrito a seguir), para ser montado em sala de aula.

\section{Síntese de informações do Quebra-cabeças n 04}

$\begin{array}{lcc}\text { DESCRIÇÃO DOS } & \text { PROCESSOS GEOLÓGICOS- } \\ \text { GEOMORFOLÓGICOS: } & \text { Este } & \text { quebra-cabeça, }\end{array}$
representativo da Era Mesozóica, período Cretáceo (65 milhões de anos atrás) deve ser trabalhado junto com o $n^{\circ}$ 03, já que se trata de processos integrados: constituição da Formação Serra Geral, o derramamento de lavas, as escarpas, os cânions e os entalhes dos morros testemunhos (Brasil, 2004).

Figura 06 - Quebra-cabeça nº 04 - Oceano Atlântico e a separação total de Gondwana

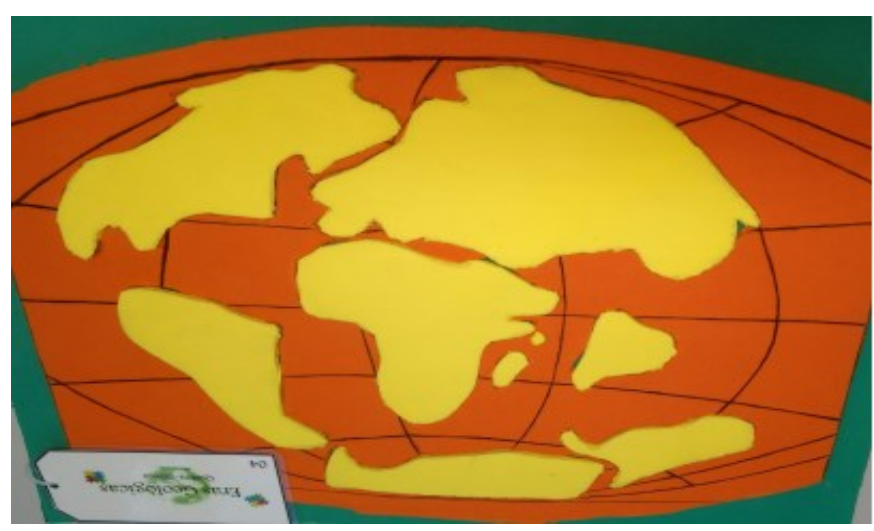

Fonte: autores (2019).
GEOSSÍTIOS DO PROJETO GCCS: Possui 14 geossítios inventariados (Godoy, Binotto \& Wildner, 2011; Geodiversidade, 2018), que apresentam uma rica diversidade paisagística. Tais geossítios podem ser agrupados em quatro tipologias: cânions, morros testemunhos, erosão diferencial e afloramento ácido. Os cânions formam quatro geossítios com vales muito profundos que estão sendo esculpidos pela ação da água. O fator preponderante no desenvolvimento dos cânions é a presença de descontinuidades tectônicas, geradoras de zonas de fraqueza por onde a água percola, facilitando a erosão vertical (Schmiguel, Vargas \& Tratz, 2009).

No território do Projeto GCCS são representados pelos geossítios Cânion da Pedra, Itaimbezinho, Malacara e Fortaleza (Godoy, Binotto \& Wildner, 2011) que constituem-se em pontos de grande interesse turístico. Já os morros testemunhos (três geossítios) tomam forma de colinas, com topos mais ou menos planos, situados na zona de recuo da escarpa, preservados da erosão pela presença de camadas mais resistentes. Representam a zona de interflúvio da rede de drenagem, orientadas em direção oeste-leste (Dantas et al, 2005). São eles: Morro dos Cabritos, Morro Carasal e Pedra Branca (Godoy, Binotto \& Wildner, 2011; Geodiversidade, 2018).

A erosão diferencial na Formação Serra Geral está ligada aos diversos graus de resistência entre as texturas dos derrames magmáticos que, trabalhados pela erosão (geralmente fluvial), formam saltos e cachoeiras. Segundo Geodiversidade (2018) são geossítios representativos desse processo a Pedra do Segredo e as Cachoeiras Magia das Águas, Ventura, da Onça, do Zelindo e da Cortina.

As ácidas de Cambará fazem parte de um geossítio de finalidade educativa e científica, inventariado por Godoy, Binotto \& Wildner (2011), que expõe as rochas vulcânicas ácidas (ricas em SiO2) em forma de fluxo de lava com bandas de diferentes cores. Estas rochas fazem parte da Fácie Palmas da Formação Serra Geral, que predomina nas cotas superiores a 930 metros, com presença de riolitos e os riodacitos (Umann et al, 2001).

METODOLOGIAS ADICIONAIS SUGERIDAS: Para ilustrar o processo de formação dos cânions, especialmente da erosão fluvial nas zonas de fratura, desenvolveu-se o modelo de simulação de formação de um cânion (material didático descrito a seguir), para ser montado em sala de aula. Dada a quantidade de geossítios inventariados sugere-se ainda, se possível, a saída de campo. Caso não seja possível, a saída em uma área próxima à escola onde haja rios ou córregos já permite trabalhar a ação erosiva da água. 
O último quebra-cabeça (número 5-figura 7) indica a posição atual dos continentes. Ele, como os demais, é uma representação momentânea de formas que são geradas pela ação de fatores endógenos e exógenos que estão em atuação ininterrupta, modelando a superfície. Pode ser explorado como ponto de partida e de chegada pelo professor, fixando a noção de que a paisagem é uma evolução e que suas formas foram (e são) elaboradas através de processos complexos e de longa duração.

Figura 07 - Quebra-cabeça nº 05 - Posição atual dos continentes

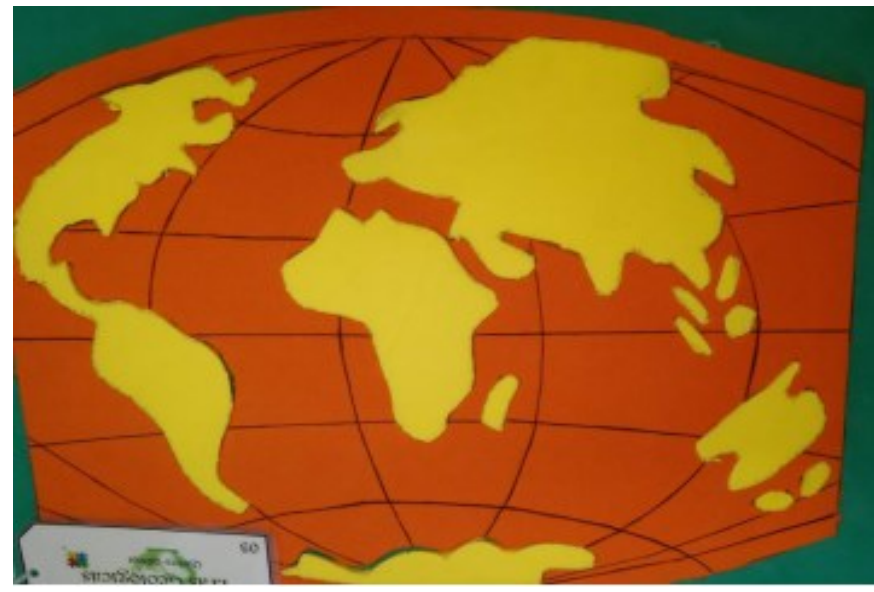

Fonte: autores (2019).

Busca-se assim contribuir para desenvolver o sentimento de valorização e de respeito à geodiversidade, bem como de ressignificação do lugar. Tal enfoque pode ser auxiliado pela utilização do Jogo de Memória (descrito a seguir), que relaciona geossítios, recursos e atrativos naturais com a explicação geocientífica dos mesmos.

\section{Modelos tridimensionais para montagem}

Constante \& Vasconcelos (2010) discutem a importância das atividades lúdico-práticas para o ensino das geociências. Martins et al (2007, p.36) designam "a atividade prática como todas as situações em que o aluno está ativamente envolvido na realização de uma tarefa" e destacam seu papel fundamental como forma de potencializar o envolvimento físico dos estudantes com o exterior.

Assim, trabalhar conceitos complexos pode se tornar mais eficaz quando os educandos são desafiados a visualizar processos e tirar conclusões a partir de materiais manipuláveis, sobretudo se estes exigirem a participação dos mesmos na sua elaboração. Tal prática pretende que o aluno exerça um papel ativo no processo de aprendizagem, possibilitando relacionar o conteúdo com seus conhecimentos prévios, incluindo os de seu lugar de vivência (Constante \& Vasconcelos, 2010).

Com este propósito, desenvolveu-se dois modelos tridimensionais para impressão em papel (preferencialmente de gramatura de $180 \mathrm{~g}$, no mínimo). Os modelos podem ser impressos pelo professor e devem ser montados pelos próprios alunos, preferencialmente durante a abordagem da temática correspondente, transformando-se em uma estratégia de integração teoria-prática.

Figura 08 - Kit para montagem do modelo tridimensional de simulação da abertura do Atlântico sul

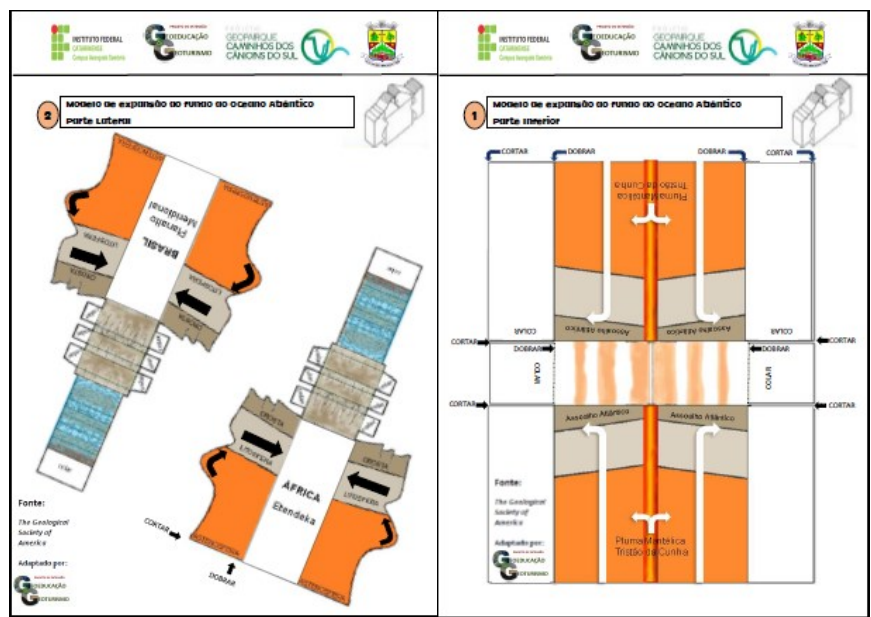

Fonte: autores (2019).

\section{Modelo tridimensional de simulação da abertura do Atlântico sul}

O modelo foi adaptado a partir do material criado pela The Geological Society of America e disponível em Constante \& Vasconcelos (2010). Após montagem, permite a simulação do movimento de divergência do fundo do Atlântico sul, facilitando a compreensão de como se deu a ruptura de Gondwana, a separação do continente africano e sul americano e a formação do próprio oceano.

Tal processo está diretamente relacionado à Formação Serra Geral e responsável pelos derrames de lavas vulcânicas há 135 milhões de anos. Destaca-se que esse processo é fundamental para a compreensão da paisagem do território do Projeto GCCS.

\section{Modelo tridimensional da formação de um cânion}

Usando a mesma estratégia, desenvolveu-se um kit para impressão que simula o processo de formação de um cânion. O modelo permite simulação da ação da água dos rios sobre fraturas e falhas pré-existentes, 
num trabalho contínuo de erosão fluvial sobre uma encosta.

Figura 09 - Modelo de simulação do cânion montado

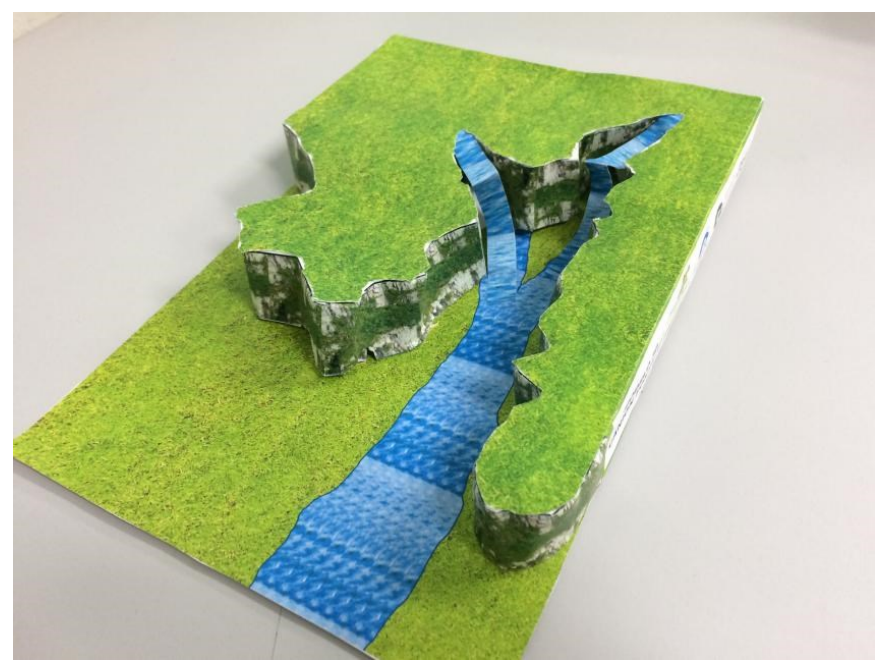

Fonte: autores (2019).

Para tal reproduziu-se parte dos contornos da encosta da Serra Geral no município de Jacinto Machado, com a inclusão de uma rede hidrográfic que pode ser movimentada pelo aluno com o uso de uma fita. Tal movimentação aprofunda a fratura da encosta e permite compreender o processo erosivo em curso.

\section{Jogo da memória}

Partindo das experiências de Santos e Moro (2010) e Moreira (2014) desenvolveu-se um jogo da memória relacionando os recursos e atrativos naturais, incluindo os geossítios inventariados no Projeto GCCS em Jacinto Machado, com informações sobre sua localização e importância para a geodiversidade e geoturismo. O jogo da memória contém 23 pares de cartas e a

Figura 10 - Jogo de memória da geodiversidade de Jacinto Machado/SC

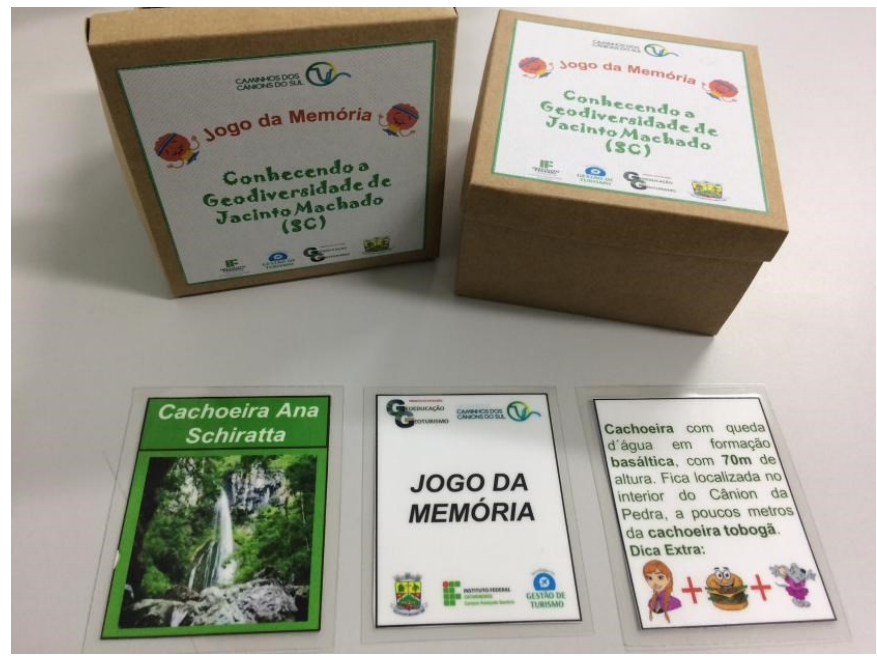

Fonte: autores (2019). descrição dos recursos/atrativos/geossítios vem acompanhada de uma dica sobre o nome dos mesmos.

Os recursos didáticos acima desenvolvidos contaram com o parecer dos docentes de Geografia das Escolas Municipais Albino Zanatta, Arizona e Figueira de Jacinto Machado/SC, através de reuniões. O objetivo foi apresentar as propostas de recursos didáticos e dialogar acerca da necessidade e utilidade dos materiais no cotidiano escolar frente ao desafio de abordar temas de geociências conectados com a realidade do Projeto.

\section{CONSIDERAÇÕES FINAIS}

O objetivo do presente estudo foi alcançado, construindo-se recursos didáticos para estudantes do $6^{\circ}$ ano da Rede Municipal de Educação Básica de Jacinto Machado, na disciplina de Geografia. O objetivo é fomentar a geoeducação como uma estratégia de valorização e conservação do patrimônio geológico local, bem como aproximar os conteúdos de geociências de sua manifestação concreta, no local de vivência do estudante. Entende-se que, em âmbito mais amplo, os produtos contribuem para consolidação do tripé Geoconservação-Geoturismo-Geoeducação no processo de construção da candidatura do Projeto GCCS.

Como desdobramento do presente estudo, os materiais acima desenvolvidos serão experimentados no cotidiano escolar com vistas à verificação de sua adequação e aplicabilidade concreta, no decorrer de 2019. Após as devidas adaptações, num processo contínuo de diálogo com os docentes que realizam o fazer pedagógico, os recursos poderão ser replicados para os demais municípios envolvidos no Projeto GCCS.

Destaca-se a importância desta pesquisa para colaborar, não somente com o território dos Caminhos dos Cânions do Sul, mas também com outras projetos que almejam o selo concedido pela UNESCO e pretendem fortalecer suas ações em prol das atividades geoturísticas e geoeducativas. Além disso, tal estudo poderá subsidiar outras pesquisas que associem as temáticas da geoeducação e do geoturismo, ainda pouco trabalhados no meio acadêmico das Ciências Sociais Aplicadas.

\section{Referências}

Alencar, R. (2013). A geodiversidade da Ilha de Santa Catarina: explorando seu valor didático no 6ㅇaㅅ ano do Ensino Fundamental. 227 f. Dissertação (Mestrado) - Curso de Geografia, Centro de Ciências Humanas, Universidade Federal de Santa Catarina, Florianópolis. 
Beltrão, L.M.V; Gomes, P.F.; Pereira Júnior, S.; Bondan, J.R.; Vargas, A.J.; Alexandre, G.C. (2018). A abordagem das geociências nos PCNs e nos Planos de Curso do 6o ano da Rede Municipal de Ensino de Jacinto Machado/SC: uma contribuição para a geoeducação no território do Projeto Geoparque Caminhos dos Cânions do Sul. Anais do VII Simpósio de Integração Científica e Tecnológica do Sul Catarinense. Araranguá: UFSC. p. 57 - 62. Recuperado em 03 de março de 2019 de http://criciuma.ifsc.edu.br/sict-sul/ images/Anais2018.pdf.

Brasil. Ministério da Educação. (2016a). Base Nacional Comum Curricular: educação é a base. $2^{a}$ versão. Brasília: MEC.

Brasil. Secretaria de Educação Fundamental. (1998a). Parâmetros Curriculares Nacionais: Ciências Naturais. Brasília: MEC/ SEF.

Brasil. Secretaria de Educação Fundamental. (1998b). Parâmetros Curriculares Nacionais: Geografia. Brasília: MEC/SEF.

Brasil. Serviço Geológico do Brasil. (2004). Excursão Virtual aos Aparados da Serra- RS/SC: aspectos geológicos e turísticos. Porto Alegre: CPRM. Recuperado em 14 de outubro de 2018 de http://www.cprm.gov.br/publique/media/ gestao_territorial/geoparques/Aparados/index.htm.

Brasil. Serviço Geológico do Brasil. (2016b). Breve História da Terra. Recuperado em 19 de outubro de 2018 de www.cprm.gov.br/publique/Redes-Institucionais/Redede-Bibliotecas---Rede-Ametista/Canal-Escola/BreveHistoria-da-Terra-1094.html.

Brilha, J. (2005). Patrimônio geológico e geoconservação: a conservação da natureza na sua vertente geológica. Braga: Palimage Editores.

Buchmann, F. (2017). Abrigo de gigantes. Revista Pesquisa FAPESP, São Paulo. Recuperado em 20 de outubro de 2018 de http://revistapesquisa.fapesp.br/2017/02/13/abrigode-gigantes.

Constante, A.; Vasconcelos, C. (2010). Actividades lúdico-práticas no ensino da geologia: complemento motivacional para a aprendizagem. Terrae Didatica. Campinas: UNICAMP, 6 (2):101-123. Recuperado em 20 de março de 2018 de https://www.ige.unicamp.br/terraedidatica/v6_2/ v6_2_A6.html

Dantas, M. E.; Goulart, D. R.; Jacques, P.D. Almeida, I. S.; Krebs, A. S. J. (2005). Geomorfologia Aplicada à Gestão Integrada de Bacias de Drenagem: Bacia do Rio Araranguá (SC), Zona Carbonífera Sul-Catarinense. In: XVI Simpósio Brasileiro de Recursos Hídricos, 2005, João Pessoa. Anais do XVI Simpósio Brasileiro de Recursos Hídricos. p. 1-20.

Geodiversidade Soluções Geológicas Ltda. (2018). Estratégia de Geoconservação do Projeto Geoparque Caminhos dos Cânions do Sul: Relatório do Inventário e Avaliação dos Geossítios. Curitiba: Geodiversidade, Produto 4, 335 p. Recuperado em 06 de agosto de 2018 de http:// www.sol.sc.gov.br/index.php/turismo/geoparque.

Gil, A. C. (2010). Como elaborar projetos de pesquisa.5. ed. São Paulo: Atlas.

Godoy, M. M.; Binotto, R. B.; Wildner, W. (2011). Geoparque
Caminhos Dos Cânions Do Sul: Proposta. Brasília: Serviço Geológico do Brasil, 2011. 109 p. Recuperado em 02 de agosto de 2018 de www.cprm.gov.br/publique/media/ gestao_territorial/geoparques/canions/ introducaocanions.html.

Leinz, V; Amaral, S.E. (1989). Geologia Geral. 11 ed. São Paulo: Nacional.

Lin, S. C.; Beltrão, L.M.V; Melo, M.D. (2016). Candidatura a Geoparque Caminhos dos Cânions do Sul: avanços do projeto. Araranguá: Secretaria de Desenvolvimento Regional.

Martins I., Veiga L., Teixeira F., Tenreiro-Vieira C., Vieira R., Rodrigues V., Couceiro F. (2007). Educação em ciências e ensino experimental. Formação de professores. Lisboa: Ministério da Educação, Direç̧ão Geral de Inovação e Desenvolvimento Curricular.

Moreira, J. C. (2014). Geoturismo e interpretação ambiental. Ponta Grossa: UEPG.

Moura-Fé, M.M.; Nascimento, R.L.; Soares, L.N. (2017). Geoeducação: princípios teóricos e bases legais. IN: Simpósio Brasileiro de Geografia Física Aplicada, 17, 2017. Anais do XVII Simpósio Brasileiro de Geografia Física Aplicada. Campinas: UNICAMP. p.3054-3065. Recuperado em 01 de março de 2018 de https://ocs.ige.unicamp.br/ojs/sbgfa/article/ view/1953.

Newsome, D.; Dowling, R. (2006). The scope and nature of geotourism. In: Dowling, R.; Newsome, D. Geotourism. Oxford: Elsevier Butterworth Heinemann, p. 3-25.

Santos, E. R. dos; Moro, P. R. (2010). Alternativas metodológicas de educação ambiental na cidade de Piraí do Sul. IN: Encontro Conversando sobre Extensão, 8, 2010. Anais do VIII CONEX. Ponta Grossa: UEPG. Recuperado em 27 de julho de 2018 de http://www.uepg.br/proex/anais/ trabalhos/8/78.pdf.

Schmiguel, K.; Vargas, K. B.; Tratz, E.B. (2009). Configuração geológico-geomorfológica e evolução da paisagem dos canyons da região de Campos de Cima da Serra -Sul do Brasil. Observatório Geográfico da América Latina. México. Recuperado em 15 de novembro de 2018 de http:// www.observatoriogeograficoamericalatina.org.mx/egal12/ Procesosambientales/.../21.pdf.

Sgardi, G.N.C.; Dardenne, M.A. (1996). Evolução climática do Gondwana nas regiões centro-sul do Brasil e seus registros geológicos. Geonomos. Belo Horizonte, v.4, n.1. p.21-49.

Triviños, A. N. S. (2011). Introdução à Pesquisa em Ciências Sociais. 1. ed. São Paulo: Atlas.

Tuan, Y. (2015). Espaço e lugar: a perspectiva da experiência. Londrina: Eduel.

Umann, L.V.; Lima, E.F.; Sommer, C.A.; Liz, J.D. (2001). Vulcanismo ácido da Região de Cambará do Sul (RS): litoquímica e discussão sobre a origem dos depósitos. Revista Brasileira de Geociências. São Paulo: USP, 31(3):357-364. Recuperado em 25 de novembro de 2018 de http://ppegeo.igc.usp.br/ index.php/rbg/article/view/10598/10094.

UNESCO. (2014). Guidelines and Criteria for National Geoparks seeking UNESCO's assistance to join the Global Geoparks 
Network (GGN). França. Recuperado em 01 de março de 2018 de http://www.unesco.org/new/fileadmin/ MULTIMEDIA/HO/SC/pdf/

sc geoparcs_2010guidelines.pdf.

Warren, L. V, et al. (2008). Evolução sedimentar da Formação Rio do Rastro (Permo-Triássico da Bacia do Paraná) na porção centro sul do estado de Santa Catarina, Brasil. Revista Brasileira de Geociências, São Paulo, v.38, n.2, p.1-15.

Winge, M. et al. (2001). Glossário Geológico llustrado. Recuperado em 19 de outubro de 2018 de http://sigep.cprm.gov.br/ glossario

\section{CONTRIBUIÇÃO dOS AUTORES}
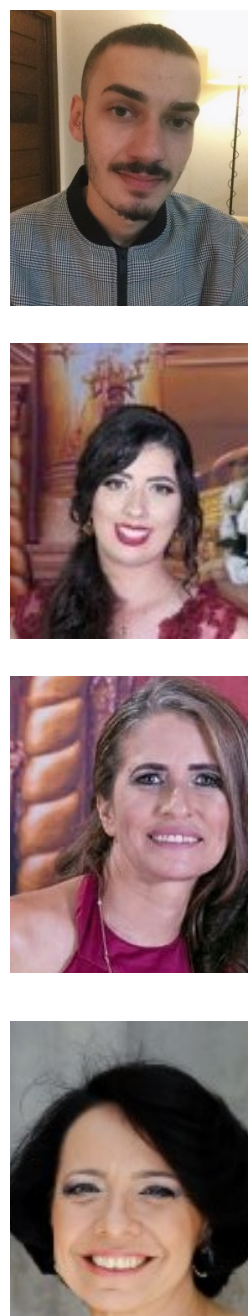

Sinval Pereira Júnior - Definição do objetivo da pesquisa; revisão bibliográfica e fundamentação teórica; escolha dos procedimentos metodológicos; análise dos resultados; elaboração de quadros e figuras; redação do manuscrito; e adequação às normas da Applied Tourism.

Patrícia Fagundes Gomes - Definição do objetivo da pesquisa; revisão bibliográfica e fundamentação teórica; escolha dos procedimentos metodológicos; análise dos resultados; e redação do manuscrito.

Janete Rodrigues Bondan - Revisão bibliográfica e fundamentação teórica; escolha dos procedimentos metodológicos; análise dos resultados; e redação do manuscrito.

Leila Maria Vasquez Beltrão Definição do objetivo da pesquisa; escolha dos procedimentos metodológicos; análise dos resultados; elaboração de quadros e figuras; redação do manuscrito; e revisão crítica. 